\title{
Exercise Addiction: A Comparison Between the Individuals Who Exercise for Physical Recreation and Who Receive Personal Exercise Training
}

\author{
Umut Davut Basoglu \\ Correspondence: Umut Davut Basoglu, High school of Physical Education and Sports, Nisantasi University, Istanbul, \\ Turkey.
}

Received: September 5, 2018

doi:10.11114/jets.v6i12.3604
Accepted: September 25, 2018

Online Published: September 28, 2018

URL: https://doi.org/10.11114/jets.v6i12.3604

\begin{abstract}
In the study, we aim to investigate the exercise addiction levels of the individuals who join sports centers for recreational activity and the ones who also receive personal exercise training. The universe of this study is the individuals who are members of The Club sports center located in Istanbul province, the European side of Esenyurt. The sample is composed of 120 members who are selected by the simple random sampling. The participants are all the members of the sports center who have regularly exercised for at least one year and continue to sports center at least two days a week. Participants have received enlightened approvals for voluntary participation either.

In order to measure exercise addiction level, we used "Exercise Addiction Scale-21" developed by Hausenblas and Downs (2002) and adapted to Turkish by Yeltep and İkizler (2007).

Frequency test is used to reveal the features of the participants. The data were not normally distributed. So Kruskal-Wallis and Mann Whitney U Tests were used for cross-group comparisons. Findings were accepted as statistically significant at $\mathrm{p}<0.05$ level.

Results show that exercise addiction levels of individuals who have received special training and those who spend more time on monthly and weekly exercise are higher than the rest.

As a conclusion, the increase in the number of days and the number of hours of exercises seems to be an antecedent, of exercise addiction. We also find out that the exercise addiction levels of individuals who receive personal exercise training are higher.
\end{abstract}

Keywords: physical recreational efficiency, exercise, addiction, exercise addiction, personal exercise training, PT

\section{Introduction}

Physical recreation or recreational physical activities are intended to improve competitiveness and mature skills that are required to be "less pretentious, to comply with rules and to be fair", as opposed to sporting competitions and performance-requiring sports. Recreational physical activities can also provide opportunities for "problem-solving skills, gaining new abilities, and trying new ways to succeed and fail" (Yaman and Arslan, 2009).

Although exercise plays an important role in "prevention of diseases and survival in a healthy way", ineffective exercise habits may result in opposite effects. Individuals can see physical and psychological harm due to prudence (Hausenblas and Downs, 2002).

Along with the definition of addiction, the concept of exercise addiction has also begun to emerge. Russell defines addiction as the "negative effects experienced in the absence of an activity, object or drug" (Veale, 1987). Those negative effects also emerge in the exercise environment.

Individuals have been observed to feel insufficient self-esteem when they experience excessive exercise-related injuries so when they cannot exercise (Hausenblas and Downs, 2002). Due to these over-exertions or psychological factors, the individual deeply wants to exercise. This is called exercise addiction. In another definition, exercise addiction is defined as "an exercise that is incompatible with the desire for physical activity and physical activity that creates negative psychological symptoms such as physical injury and anxiety and depression" (Cook et al., 2015). According to Vardar (2012), exercise addiction is "a state of being over-willing to exercise physical exercise and doing exercise, even though the exercise has harmful effects, for example, exercising even in case of disability and feeling bad when hindered". 
When the concept exercise addiction is examines, three main components appear in the literature. The first is the "tolerance" (the increase in the amount of exercise to achieve the desired effect, or the decrease in the effect of continuing to exercise in the same amount), the second is the "withdrawal effect" (when the behavior is inhibited, the negative effect is seen - the feeling of deprivation) (repetition of behavior to avoid stress and anxiety) (Adams, Miller and Kraus, 2003).

In the extant literature, exercise addiction is studied as "negative and positive addiction" in two opposing ways. The researchers define those addiction types under some specific conditions. "Positive addiction" is considered to be an excessive exercise in order to cope with the difficulties encountered and encountered in individuals' daily lives or at any moment in their lives. "Negative addiction", on the other hand, appears, when an overexercising individual cannot exercise, as anxiety, depression, nervousness, insomnia, etc. when he (Hausenblas and Downs, 2002).

Another classification regarding exercise addiction is "primary and secondary exercise addiction". Exercise behavior, which is a problem in primary exercise addiction, has a psychological and physical connection which is the act of doing with passion in order to lead to loss of function and not leaving it. Secondary exercise addiction is the subject of compensatory behaviors in support of weaknesses due to eating disorders (Veale, 1987).

In previous studies, exercise addiction is examined with various variables. In those studies, exercise addiction was found to be associated with personality traits, psychological factors, physiological factors, type of exercise, gender and years of participation in exacerbation (Back, 2016). However, no study has been found on the level of exercise addiction of individuals in personal exercise training. Accordingly the aim of this paper is to investigate the exercise addiction levels of the individuals who join sports centers for recreational activity, such as engaging fitness centers and regular sports, and the ones who also receive personal exercise training with personal trainers (PT).

\section{Method}

In this study, the relational screening model is used to examine the exercise addiction levels of individuals who attend sports centers for recreational activities and receive special exercise training.

The universe of this study is the individuals who are members of The Club sports center located in Istanbul province, the European side of Esenyurt. The sample is composed of 120 members who are selected by the simple random sampling. The participants are all the members of the sports center who have regularly exercised for at least one year and continues to sports center at least two days a week. Participants have received enlightened approvals for voluntary participation either.

The summary of the scales used is given below

Exercise Addiction Scale-21 (EB-21): developed by Heather A. Hausenblas from the Department of Exercise and Sports Sciences of the University of Florida, Exercise Laboratory and Daniel Symons Downs from the Department of Exercise Psychology of the Kinesiology Department of Pennsylvania State University, in five steps. As a result of the test-retest technique, the scale was found statistically significant at $\mathrm{p}<0.001$. In addition, the alpha coefficient was calculated as 0.95 , perfectly. The scale can be on individuals or groups that are composed of individuals over 18 years. The answers were arranged according to the 6-point Likert Scale, in which 1 refers to "would be" while 6 refers to "always". The duration of the response to the Exercise Addiction Scale-21 was estimated to be approximately 5 minutes in total. The Turkish version of the scale was developed by Yeltepe and İkizler (2007). Based on the criteria of substance addiction in DSM-IV (Diagnostic and Statistical Manual of Mental Disorders - IV), EBÖ-21, consisting of 21 questions, gives the following information:

1- Averages of score (s) of exercise addiction symptoms.

2- Differentiation of the following types from each other:

a) Exercise addict

b) Non-dependent symptomatic

c) Non-dependent asymptomatic

3- Identification of the following situations in individuals:

a) Physiological addiction (tolerance/withdrawal symptoms)

b) No physiological addiction (absence of evidence for discontinuation of exercise intolerance)

In the Exercise Addiction Scale-21, seven addiction criteria were identified and individuals who met three or more of these criteria were classified as exercise addicts. Addiction interval is determined by taking 5 or more scores of the items forming the criteria. Individuals who take score in these ranges between 3 and 4 are classified as symptomatic, and these individuals may theoretically be at risk of exercise addiction. Finally, the individuals who take scores in the 
range between1-2 are classified as asymptomatic (Yeltepe and İkizler, 2007).

The data is analyzed by statistical program SPSS 22.0 (Hausenblas and Downs 2002). Frequency test is used to reveal the features of the participants. The data were not normally distributed. So Kruskal-Wallis and Mann Whitney U Tests were used for cross-group comparisons. Findings were accepted as statistically significant at $p<0.05$ level.

\section{Results}

Table 1. Demographic characteristics of participants

\begin{tabular}{|c|c|c|c|c|c|}
\hline \multicolumn{2}{|c|}{ Variable } & Frequency & Percent & Valid Percent & Cumulative Percent \\
\hline \multirow{6}{*}{ Age } & $16-20$ & 20 & 16.7 & 16.7 & 16.7 \\
\hline & $21-25$ & 28 & 23.3 & 23.3 & 40.0 \\
\hline & $26-30$ & 13 & 10.8 & 10.8 & 50.8 \\
\hline & $31-35$ & 28 & 23.3 & 23.3 & 74.2 \\
\hline & $36-40$ & 12 & 10.0 & 10.0 & 84.2 \\
\hline & Over 41 & 19 & 15.8 & 15.8 & 100.0 \\
\hline \multirow[b]{2}{*}{ Gender } & Female & 48 & 40.0 & 40.0 & 40.0 \\
\hline & Male & 72 & 60.0 & 60.0 & 100.0 \\
\hline \multirow{3}{*}{ Education level } & Vocationalschool & 20 & 16.7 & 16.7 & 16.7 \\
\hline & Undergraduate & 64 & 53.3 & 53.3 & 70.0 \\
\hline & $\begin{array}{l}\text { Post graduate (master } \\
\text { or Ph.D) }\end{array}$ & 36 & 30.0 & 30.0 & 100.0 \\
\hline \multirow{2}{*}{$\begin{array}{l}\text { Do you get private } \\
\text { training? }\end{array}$} & Yes & 70 & 58.3 & 58.3 & 58.3 \\
\hline & No & 50 & 41.7 & 41.7 & 100.0 \\
\hline \multirow{2}{*}{$\begin{array}{c}\text { How many weeks do } \\
\text { you exercise per a } \\
\text { month? }\end{array}$} & 3 weeks & 52 & 43.3 & 43.3 & 43.3 \\
\hline & 4 weeks & 68 & 56.7 & 56.7 & 100.0 \\
\hline \multirow{4}{*}{$\begin{array}{c}\text { How many days do } \\
\text { you exercise per a } \\
\text { week?? }\end{array}$} & 2 days & 20 & 17.3 & 13.3 & 16.7 \\
\hline & 3 days & 72 & 56.0 & 56.0 & 76.7 \\
\hline & 4 days & 16 & 13.3 & 13.3 & 90.0 \\
\hline & 5 days & 12 & 10.0 & 10.0 & 100.0 \\
\hline
\end{tabular}

Table 1 shows the demographics of the participants. According to the table; $16.7 \%$ of the participants are 16-20 years, $23.3 \%$ are $21-25$ years, $10.8 \%$ are $26-30$ years, $23.3 \%$ are $31-35$ years, $10 \%$ were 40 years and $15.8 \%$ of them were over 41 years old. $40.0 \%$ of the participants were female while $60.0 \%$ were male. According to educational status; $16.7 \%$ of the participants graduated from vocational schools, $53.3 \%$ were undergraduate and $30.0 \%$ were postgraduates. $42.5 \%$ of participants have been keeping doing exercise for $1-3$ years, $40.0 \%$ for $4-6$ years and $17.5 \%$ for $7-9$ years. $43.3 \%$ of the participants were exercising for 3 weeks per month and $56.7 \%$ for 4 weeks per month; $58.3 \%$ of the participants were getting private training while and $41.7 \%$ were not. And finally $17.3 \%$ of the participants exercising for 2 days, $56 \%$ for 3 days, $13.3 \%$ for 4 days and $10 \%$ for 5 days per week.

Table 2. Mann Whitney U test for exercise addiction levels of individuals

\begin{tabular}{cccccc}
\hline Variable & & $\mathrm{n}$ & Mean & $\mathrm{f}$ & $\mathrm{p}$ \\
\hline \multirow{2}{*}{ Do you get private training? } & Yes & 70 & $3.85 \pm .522$ & \multirow{2}{*}{2.818} & $\mathbf{0 . 0 3 6 *}$ \\
& No & 50 & $3.11 \pm .319$ & & \\
\hline
\end{tabular}

* Significance level: $p<0.05$

Table 2 shows the results of Mann Whitney U test for exercise addiction levels of individuals who get private training and who do not. The findings show a statistically significant difference $(p<0.05)$ between the ones that get private training and that are not. Individuals who get private training have higher scores than those who do not get.

Table 3. Average values for monthly exercise frequency, weekly exercise frequency and total addiction score

\begin{tabular}{|c|c|c|c|c|}
\hline \multirow[b]{2}{*}{ Groups } & \multicolumn{4}{|c|}{ Frequency of exercise per month ${ }_{\text {Frequency of exercise ner week (day)Total Addiction Score }}$} \\
\hline & $\mathbf{n}$ & $\begin{array}{r}\text { (week) } \\
\text { x } \pm \text { s.d. }\end{array}$ & $x \pm$ s.d. & $x \pm$ s.d. \\
\hline Addicted & 21 & $3.85 \pm 1.71$ & $4.90 \pm 0.51$ & $97.58 \pm 12.81$ \\
\hline Symptomatic 6 & 67 & $2.87 \pm 1.03$ & $2.62 \pm 0.77$ & $55.24 \pm 10.51$ \\
\hline Asymptomatic 3 & 32 & $2.01 \pm 1.12$ & $2.18 \pm 0.46$ & $39.62 \pm 9.46$ \\
\hline
\end{tabular}

In order to see whether there are any significant differences between addicted, symptomatic and asymptomatic groups regarding monthly exercise frequency, weekly exercise frequency and total addiction score the data is submitted to Kruskal-Wallis test. The results show that monthly exercise frequency, weekly exercise frequency and total addiction scores significantly differ between addicted, symptomatic and asymptomatic groups. To find out which group is significantly different than the rest, we used Mann-Whitney U Test. The findings reveal that addicted group is significantly different than the symptomatic and asymptomatic ones. The means and the standard deviations for addicted, symptomatic and asymptomatic groups regarding monthly exercise frequency, weekly exercise frequency and 
total addiction scores is given at table 3. Addicted group; (i) has a higher monthly exercise frequency $(3,85 \pm 1,71$ weeks), (ii)has been exercising more days in terms of weekly exercise frequency (3,90 $\pm 0,51$ days) and has a higher total addiction score $(97.58 \pm 12.81)$ than the other groups.

\section{Discussion}

In this study, we aim to investigate the exercise addiction levels of the individuals who join sports centers for recreational activity and receive special exercise training. Of the 120 participants, 21 is found to be exercise addicted, 67 show symptomatic symptoms, while 32 show asymptomatic symptoms. The exercise-addicted group is found to join more daily exercise per month and week than the other groups. In addition, the findings reveal that the exercise addiction levels of the individuals receiving special exercise training are higher than the rest.

Similar to our findings, the previous studies provide empirical evidence regarding the positive association between the exercise addiction and the higher duration of exercise and the higher frequency of exercise (Hausenblas et al., 2002; Baekland, 1970). Moreover, the results of a study conducted by Bavli et al., (2011) concerning the effect of regular exercise on exercise addiction, shows that among the 10 of 140 participants were found to be exercise addicted on 1,95 were symptomatic while 35 were asymptomatic. In addition; the addicted group is found to have statistically different scores regarding weekly exercise frequency, exercise age and total addiction scores than symptomatic and asymptomatic groups.

The comprehensive literature review demonstrates that personality traits and psychological factors also have a potential to play an important role in the exercise addiction levels and other exercise addiction-related variables. For instance, Cohen (1995) reports that exercise addiction levels are higher in individuals who experience weight anxiety, who have low self-esteem, low self-esteem and who feel a higher need for success. On the other hand Cook (1996) provides empirical evidence in support of the relationship between compulsive behaviors, perfectionism and exercise addiction on 155 aerobic trainers. Moreover Davis et al. (1995) address that individual, who have obsessive-compulsive behavior disorder, eating disorder, and fear of weight gain, are more likely to be exercise addicted. Another study by Kagan (1987) on addictive personality factors finds out that the addiction scores of those who had more years of exercise participation are significantly higher than the others. In contrary, the results of another study conducted on 106 male and 99 female participants who exercise for average 7 hours per week, shows no significant relationship between excessive exercise and dysfunctional personality traits such as lower self-esteem, greater obsessive-compulsiveness and external control focus (Tiggemann, 1997).

The extant literature bound of studies concerning exercise addiction on athletes. A paper on marathon runners exposes that female runners had higher statistical significance of exercise addiction scores than men (Pierce et al., 1997). Another paper, from the perspective of sports types, show that professional athletes have higher exercise addiction scores than amateur athletes and amateur weightlifters (Hurst et al., 2000). Furthermore, Pierce et al. (1993) find that female ballets and modern dancers have higher addiction scores than female runners and female grass hockey athletes. In addition, athletes who engage in bodybuilding and weightlifting sports are shown to have a higher exercise addictions score than those who go to the fitness center (Hale et al., 2010).

As a sum, we find out that as the frequency of exercise in terms of days per week and hours per day increases, so the level of exercise addiction increases either. Moreover, our findings show that the exercise addiction level of the individuals taking the personal exercise training is higher than the others. We think that the reason underlying the increase in the exercise addiction may be the personal traits and psychological disorders or. For instance individuals who are overweight or who have poor body image, may feel uncomfortable in group exercising, so they may prefer to exercise with personal exercise classes.

\section{References}

Adams, J. M., Miller, T. W., \& Kraus, R. F. (2003). Exercise addiction: diagnostic and therapeutic issues for patients in psychotherapy. J. Contemp. Psychother, 33, 93-107. https://doi.org/10.1023/A:1022883104269

Back, J. (2016). Profiles of Exercise Addiction - A person centred approach to study potential mechanisms. Sport and Exercise Psychology, 30, 91-120.

Baekland, F. (1970). Exercise Deprevation: Sleep and Psychological Reactions. Archives of General Psychiatry, 22, 365-369. https://doi.org/10.1001/archpsyc.1970.01740280077014

Bavlı, Ö., Kozanoğlu, M. E., \& Doğanay, A. (2011). Düzenli Egzersize Katılımın Egzersiz Bağımlılığı Üzerine Etkisi. Selçuk Üniversitesi Beden Eğitimi ve Spor Bilim Dergisi, 13(2), 150-153.

Cohen, R. (1995). Video interviews: "Hooked" on exercise. In J. Annett, B. Cripps, \& H. Steinberg, Exercise addiction: Motivation for participation in sport and exercise (pp. 54-59). Leicester, UK: British Psychological Society. 
Cook, B., Hausenblas, H., Crosby, R. D., Cao, L., \& Wonderlich, S. A. (2015). Exercise addiction as a mediator of the exercise and eating disorders relationship: A pilot study. Eating Behaviors, 16, January, 9-12. https://doi.org/10.1016/j.eatbeh.2014.10.012

Cook, C. A. (1996). The psychological correlates of exercise addiction in aerobics instructors. Unpublished master's thesis, University of Alberta, Alberta, Canada.

Davis, C., Kennedy, S. H., Ralevski, E., Dionne, M., Brewer, H., Neitzert, C., \& Ratusny, D. (1995). Obsessive compulsiveness and physical activity in anorexia nervosa and high-level exercising. Journal of Psychosomatic Research, 39, 967-976. https://doi.org/10.1016/0022-3999(95)00064-X

Hale, B. D., Roth, A. D., DeLong, R. E., \& Briggs, M. S. (2010). Exercise addiction and the drive for muscularity in male bodybuilders, power lifters, and fitness lifters. Body Image, 7(3), 234-239. https://doi.org/10.1016/j.bodyim.2010.02.001

Hausenblas, H. A., \& Downs, D. S. (2002). Exercise addiction: a systematic review. Psychology of Sport and Exercise, 3, 89-123. https://doi.org/10.1016/S1469-0292(00)00015-7

Hurst, R., Hale, B., Smith, D., \& Collins, D. (2000). Exercise addiction, social physique anxiety, and social support in experienced and inexperienced bodybuilders and weightlifters $\mathrm{Br}$. J. Sports Med., 34, 431-435. https://doi.org/10.1136/bjsm.34.6.431

Iannos, M., \& Tiggemann, M. (1997). Personality of the excessive exercisers. Personality and Individual Differences, 22, 775-778. https://doi.org/10.1016/S0191-8869(96)00254-1

Kagan, D. M. (1987). Addictive Personality Factors. Journal of Sport Medicine; 121, 553-538.

Pierce, E. F., Daleng, M. L., \& McGowan, R. W. (1993). Scores on exercise addiction among dancers. Perceptual and Motor Skills, 76(2), 531-535. https://doi.org/10.2466/pms.1993.76.2.531

Pierce, E. F., Rohaly, K. A., \& Fritchley, B. (1997). Sex differences on exercise addiction for men and women in a marathon road race. Percept Mot Skills, 84, 991-994. https://doi.org/10.2466/pms.1997.84.3.991

Vardar, E. (2012). Egzersiz Bağımlılığı. Archives Medical Review Journal, 21(3), 163-173.

Veale, D. (1987). Exercise Addiction. British Journal of Addiction, 82(1987), 735-740.

Yaman, M., \& Arslan, S. (2009). Çocuk ve Gençlik Suçlarının Önlenmesinde Rekreatif Sporlar, Uluslararası İnsan Bilimleri Dergisi, 6(1), 445-459.

Yeltepe, H. C. (2007). İkizler, Egzersiz Bağımlılığı Ölçeği-21'in Türkçe Geçerlilik Ve Güvenilirlik Çalışması, Bağımlılık Dergisi, 8(1), 29-35.

\section{Copyrights}

Copyright for this article is retained by the author(s), with first publication rights granted to the journal.

This is an open-access article distributed under the terms and conditions of the Creative Commons Attribution license which permits unrestricted use, distribution, and reproduction in any medium, provided the original work is properly cited. 